\title{
LAS ESCUELAS POÉTICAS ESPAÑOLAS EN LOS ALBORES DE LA HISTORIOGRAFÍA LITERARIA: ARJONA Y REINOSO
}

\author{
Begoña López Bueno
}

El siglo XIX ofrece una sucesión ininterrumpida de iniciativas tendentes a la organización del patrimonio literario español y a su estudio sistemático. Tal despliegue abre y cierra el siglo con dos figuras de excepcional importancia: Manuel José Quintana, hombre formado en el XVIII y que sentó bases fundamentales para la crítica del siglo siguiente (un siglo, por lo demás, y pese a la etiqueta de romántico, de preferentes criterios clasicistas) y Marcelino Menéndez Pelayo, resumen y compendio de la historiografía decimonónica y puerta grande de entrada a la del XX. Entre uno y otro se sucede la nómina de beneméritos investigadores, que tanto atesoraban el parnaso con infatigables búsquedas (he ahí el Ensayo de una biblioteca española de libros raros y curiosos de Bartolomé José Gallardo), cuanto establecían las bases de la moderna historia literaria en obras tan valiosas como la Historia crítica de la literatura española de José Amador de los Ríos. En ese sentido de historiar el legado literario distintas fueron - preludio de los futuros «manuales»-, aunque por menos significadas no dejaron de ser importantes, las historias de la literatura española vistas por los ojos extranjeros de Sismondi, Ticknor y Fitzmaurice-Kelly.

No es mi propósito entrar aquí en estos aspectos generales de la historiografía literaria (aunque sí aprovecho — cualquier ocasión es buena- para expresar mi agradecido homenaje a esos titanes de la erudición decimonónica de cuyos beneficios nos sustentamos, y si ya no de sus planteamientos críticos, no es por demérito suyo; es simplemente un tributo a los tiempos: que cada cual es hijo del suyo y de sus patrones ideológicos y estéticos). El objetivo de estas páginas es el estudio de un pequeño opúsculo que se sitúa en los mismos inicios de la historiografía literaria española aplicada a la poesía. Se trata del Plan para una historia filosófica de la poesía española del que es autor el poeta y clérigo sevillano Manuel María de Arjona. El breve discurso - fue concebido, como veremos, pa- 
ra ser leído en la Academia particular de Letras Humanas de Sevilla- se publicó en 1806 en el Correo Literario y Económico de Sevilla, y fue seguido de unas $R e$ flexiones sobre el Plan..., publicadas en el mismo periódico y año, del también poeta, clérigo y amigo de Arjona, Félix José Reinoso ${ }^{1}$.

Adelantaré desde ahora que el mayor mérito de este pequeño tratado que constituyen el Plan de Arjona y las Reflexiones de Reinoso no está en su valor absoluto, sino en el relativo de su primacía en intentar establecer una historia razonada («filosófica») de la poesía española. Esta ha sido la circunstancia que me ha llevado a detenerme en él, máxime tras verla ratificada con la autoridad de Menéndezd Pelayo: «El proyecto de Arjona, parto de un entendimiento elevado, merecía, pues, elogio como primera tentativa encaminada a poner orden en el estudio hasta entonces rutinario y empírico de la poesía española» ${ }^{2}$. Don Marcelino, que no deja de señalar algunos de los principales defectos del Plan, no menciona, sin embargo, las más atinadas Reflexiones de Reinoso, que impugnan ya varios deslices de su amigo. Es probable que el bibliógrafo no conociera sino el discurso de Arjona, pues posiblemente - y como luego trataré de explicar- ambas piezas pertenecen a dos momentos distintos: Arjona leería su Plan en la Academia particular de Letras Humanas en los últimos años del 1700 y Reinoso reflexionaría más tarde sobre el mismo, en la fecha que aparece su colaboración en tres entregas en el Correo de Sevilla de 1806.

Ambos opúsculos, sus autores y la Academia particular de Letras Humanas, de la que Arjona y Reinoso fueron inspiradores y miembros destacados, se explican en un ambiente que es preciso referenciar al menos en sus elementos principales. Tal ambiente surge del impulso regenerador de las letras hispalenses emprendido desde fines del siglo XVIII por un grupo de jóvenes cuyo plantel principal se fija en los nombres de Arjona, Reinoso, Blanco y Lista, a los que hay que añadir otros de segunda fila como Roldán, Castro, Núñez-Díaz, Mármol e Hidalgo. Sus aires renovadores se enmarcan en la tradición clasicista, siguiendo para ello el ejemplo de sus contemporáneos salmantinos, pero buscando al mismo tiempo sus señas de identidad estética en la poesía sevillana del Siglo de Oro, de la que se sienten continuadores como segunda o moderna escuela poética sevillana. Los avatares, así como las pretensiones y los logros poéticos del grupo fueron historiados con fervorosa añoranza años más tarde por Alberto Lista ${ }^{3}$, y con más distanciamiento crítico por Leopoldo Augusto de Cueto, quien, haciéndose eco de los juicios de Antonio Alcalá Galiano, no deja de señalar cierto pseudoclasicismo

1 D. M. M. de A., «Plan para una historia filosófica de la poesía española», Correo Literario y Económico de Sevilla, n. 294 de 23 de julio de 1806, pp. 113-119. D. F. J. R., «Reflexiones sobre el Plan para una historia filosófica de la poesía española», Idem, n. 300 de 13 de agosto de 1806, pp. 161-163; n. 301 de 16 de agosto, pp. 169-173; y n. 302 de 20 de agosto, pp. 177-179. Todos los números citados se encuentran recogidos en el tomo IX, junio-septiembre de 1806, del periódico, que se guarda en la Hemeroteca de Sevilla.

2 Historia de las ideas estéticas en España, tomo III, vol. 2․, Madrid, Imp. de A. Pérez Dubrull, 1886, p. 263.

3 «De la moderna escuela sevillana de literatura», Revista de Madrid, I, 1838, pp. 251-276. 
y amaneramiento en estos poetas sevillanos en su afán de imitar a los clásicos ${ }^{4}$. Menéndez Pelayo equilibra la mirada crítica dando más vuelos metodológicos al concepto de escuela y mayor mérito a la labor de esta moderna sevillana ${ }^{5}$. Poco aportó sin embargo a la historia de este grupo poético el estudio más extenso que le dedicó Angel Lasso de la Vega y Argüelles, sucesión interminable de panegíri$\cos \sin$ apenas juicio crítico de valor ${ }^{6}$.

Pues bien, este grupo sevillano de fines del XVIII y principios del XIX fundó como su órgano institucional la Academia particular de Letras Humanas y contó con el Correo Literario y Económico de Sevilla, dirigido por Justino Matute y Gaviria, como medio difusor de sus ideas. La Academia de Letras Humanas (que había sido precedida de otro intento, la Academia Horaciana, fundada por Arjona y Matute) no es sino el resultado natural de una estética comulgante con la norma clasicista (puesta de manifiesto en el discurso de Arjona Sobre la necesidad de establecer Academias en España como el único medio de adelantar la literatura). Vivió entre mayo de 1793 y mediados de 1803, aunque su influencia se extendió mucho más allá por la labor continuada de sus miembros, y se ubicó primero en la Biblioteca Pública de San Acacio y a partir de 1799 en el Colegio de Santa María de Jesús.

La finalidad principal de esta Academia fue el cultivo de la poesía lírica acompañado del «examen de los mejores libros sobre Bellas Letras», dándose en este sentido especial preferencia a los Principios de Literatura de Batteaux ${ }^{7}$. Así, en sus juntas se leían los versos de sus componentes ${ }^{8}$, se establecían certámenes poéticos ${ }^{9}$ y se discutía sobre preceptiva y cuestiones referidas a la historia y a la teoría literaria ${ }^{10}$. En esta dirección encaja el Plan para una historia filosófica de la poesía española que Manuel María de Arjona leyó en una de sus sesiones.

4 «Bosquejo histórico-crítico de la poesía castellana en el siglo XVIII», en Poetas líricos del siglo XVIII, I, BAE, tomo LXI, nueva ed., Madrid, 1952, pp. CLXXXV-CXCVIII.

5 Historia de las ideas estéticas, ob. cit., III, pp. 252-270.

6 Historia y juicio crítico de la escuela poética sevillana en los siglos XVIII y XIX, Madrid, Imp. de Manuel Tello, 1876.

7 Cfr. Menéndez Pelayo, ob. cit., pp. 253-254.

8 Es el caso de las poesías de Reinoso, Blanco y Lista luego colectadas y publicadas con el título de Poesías de una Academia de Letras Humanas de Sevilla, Sevilla, Viuda de Vázquez y Cía., 1797. El tomo va precedido de una curiosa defensa de la institución (Vindicación de aquella Junta, escrita por su individuo D. Eduardo Adrián Vacquer, Presbitero, contra los insultos de un impreso con el título de Carta Familiar de Don Myas Sobeo a Don Rosauro de Safo) que nos hace comprender que la existencia de la Academia no fue ajena al ataque y a la polémica. Años más tarde hay otro testimonio: Tomás José González Carvajal publica en 1804 en El Regañón, periódico madrileño, una Carta al editor del Correo de Sevilla sobre la oda a la Resurrección del Señor. La oda en cuestión había sido escrita por José María Roldán, y los miembros de la Academia, ya disuelta en esas fechas, encargaron a Reinoso la respuesta, que la dio por extenso y bajo el pseudónimo de El Capitán D. Francisco Hidalgo Muñatones, vecino de Vara del Rey (Correo Literario y Económico de Sevilla, tomo IV, octubre 1804-enero 1805).

9 Como el fijado sobre el tema «la caída de nuestros primeros padres», en el que fueron competidores Lista y Reinoso. La Academia adjudicó el premio al segundo el 8 de diciembre de 1799 por su poema La inocencia perdida, que se publicó posteriormente en 1804.

10 De hecho los participantes en la Academia, y en concreto Arjona y Reinoso, además de poetas, fueron tratadistas en diversos temas, particularmente en los relacionados con literatura y huma- 
El plan propuesto por Arjona se basa en que «la historia de la poesía debe escribirse por escuelas, así como se escribe la de la pintura», método que comporta «la incomparable ventaja de clasificar el estilo de nuestros poetas, y subdividir después estas clases mayores en otras subalternas». Tras marcar los límites que abarcará su diseño histórico (y que fija en los dos siglos y medio que van de Garcilaso a la mitad del XVIII), traza el apunte de las siguientes escuelas poéticas:

Primera escuela italo-hispana. Es la fundada por Boscán y capitaneada por Garcilaso. «Llamo a esta escuela primera, porque sus copias de los italianos (a quienes siempre imitan, aun cuando parezca que imitan a los griegos y latinos) son muy imperfectas y demasiado serviles».

Segunda escuela italo-hispana o sevillana. «Esta escuela aunque dimanada de la primera, es ya enteramente perfecta en su género. Su fundador fue Fernando de Herrera». A pesar de que a este autor le falte "amena variedad», y en eso sea seguido por sus discípulos (sobre los que hace una importante matización: «advierto que no todos los poetas sevillanos son de esta escuela sevillana»), «son el mejor tesoro del lenguaje poético español».

Escuela latino-hispana. Es la del «incomparable» fray Luis de León, de «gusto enteramente latino». El inició una «nueva senda» que «ha quedado en vano abierta».

Escuela greco-hispana, representada por el Bachiller de la Torre y Villegas. «Estos dos poetas, aunque en distinto género, son enteramente griegos en sus piezas escogidas», pero el último «tiene algunas que ni son griegas ni latinas, ni de algún estilo digno de aprobación».

Escuela propiamente española. «Algunos poetas españoles, de genio original, imitando a los italianos, griegos y latinos, lo hicieron con tal maestría, que produjeron un nuevo género de poesía [...] tan propio de la lengua española, que ninguna otra lo podrá copiar». Los artífices fueron Balbuena y Lope de Vega, aunque también «Góngora en sus buenas poesías». Pertenecen también a esta escuela toda la poesía dramática y los poetas épicos.

Escuela aragonesa o de los Argensolas. Inventores de «un nuevo estilo, también propiamente español, aunque muy distinto del de Lope», caracterizado por «la filosofía sensata y la dureza no desagradable de metro».

Escuela corrompida española. «Este honor de mala originalidad nos lo trajo Góngora, cuya depravación de estilo es tan suya, que nada tiene que ver con la italiana del caballero Marini». Sin embargo, «aun en las malas obras de Góngora se encuentra un fondo riquísimo que una mano diestra podrá entresacar con utilidad». Escuela de epigramatistas. «Escuela separada porque el genio español se ha manifestado muy original en ella». Se podrían incluir en la misma también los poemas jocosos como la Gatomaquia, la Mosquea, etc.

Finalmente Arjona, bajo el epígrafe de Poetas sueltos, sitúa a aquellos «de corto mérito» $\mathrm{y}$ «que o no tienen un carácter decidido o han formado uno poco digno de aprecio» (como Pantaleón Aznar o Andrés Rey de Artieda).

nidades (Cfr. L. A. de Cueto, Poetas líricos del siglo XVIII, ob. cit., I, pp. 191-195; II, pp. 499-504; y III, pp. 207-211). 
Antes de concluir el Plan, y tras haber señalado que «si este pensamiento pues agradara, no me sería difícil reducir a estas clases todos los poetas españoles», propone una serie de recetas o «mezclas» entre las diversas escuelas para conseguir el mejor estilo posible. Así, el que quiera imitar la sevillana, hará bien en mezclar la dicción de Herrera con la amenidad de la greco-hispana o con la gallarda lozanía de la española; a la de fray Luis se le podrá añadir más sonoridad en el metro, algo de la greco-hispana, poco de la sevillana, etc. Pero en esta imitación de los modelos no debe olvidarse a los franceses y a los italianos, y, en fin, entre los antiguos Horacio siempre será la mejor guía: «así que el medio de excederlos a todos es imitarlos a todos».

¿Qué decir de este Plan de Arjona? En un primer acercamiento dos características saltan a la vista: su esquematismo y su doble finalidad. Respecto al primero, y como su propio nombre indica, no es sino un esbozo que habría que desarrollar más por extenso: «Ofrezco solamente un plan, o como un diseño de mis ideas, para si estas merecen la aprobación de los literatos darles la extensión debida». Y en cuanto a los objetivos, queda claro que junto al puramente especulativo o teórico, el Plan de Arjona tiene otro evidente: el normativo y pragmático - muy acorde con los supuestos de la institución en que fue leído- de adoctrinar a los jóvenes poetas contemporáneos. Así se pone de manifiesto desde el principio del discurso: el método de historiar la poesía española por escuelas ofrece la oportunidad de «desempeñarse con mucha libertad y desahogo la comparación entre unas y otras, para deducir (lo que hasta ahora ninguno ha hecho) o cuál sea la mejor, o qué mezcla se pueda hacer de las bellezas de todas, para que nuestros modernos poetas puedan emular y aun exceder la gloria de los antiguos». Consecuente con este objetivo, hace Arjona al final la propuesta de «mezclas» de estilos de las diversas escuelas — sin duda la parte más mostrenca, la menos válida del Plan - según el principio de la imitación compuesta de los mejores dechados.

Más importante es la faceta especulativa de operar con una sistemática en el estudio histórico de la poesía española, sistemática que deriva —como pretende Arjona- del material mismo estudiado. Por ello son fundamentales los criterios de clasificación. A este respecto vemos que procede con un principio rector, que es de nuevo el de la imitación (base fundamental en el concepto de escuela como magisterio asumido por discípulos). Pero este criterio de clasificación no rige siempre . Así, si vale para la primera y segunda escuelas italo-hispanas, para la greco-hispana y aun, aunque sea operando ex contrario o por ausencia - modo de proceder ya harto discutible- para la española, que sería por tanto la más genuina, se olvida para las demás, que clasifica, bien bajo el prisma de lo geográfico (la aragonesa de los Argensola, a falta de cualquier otra denominación mejor y tal vez autorizado por el calificativo de sevillana aplicado a la segunda italohispana), bien de lo valorativo (la española corrompida) y hasta de lo genérico (la de los epigramatistas).

Esta arbitrariedad en el principio de clasificación resiente por su base el Plan, al margen de otros defectos nada desdeñables. Menéndez Pelayo señaló algunos: el olvido de la poesía medieval y de los poetas del XVI que metrificaron en formas populares o en imitación del siglo anterior, la consideración de la poesía de 
Garcilaso meramente como italo-hispana y el haber creado una fantástica escuela greco-hispana ${ }^{11}$. A estas carencias y errores se les pueden añadir todavía otros, como la indefinición, por amplitud, de la escuela española en su acarreo de géneros líricos, dramáticos y épicos, por no hablar del casillero de poetas sueltos, principal objeción de Reinoso en sus posteriores Reflexiones sobre el Plan... Conviene, por tanto, reseñar éstas, que impugnan algunos de los más graves errores de Arjona, antes de pasar a una valoración conjunta de ambos opúsculos como inicio de la historiografía poética española.

Con el ánimo de «un verdadero amigo», Féliz José Reinoso señala la primera y más grave deficiencia del Plan: «¿Pero es tan cierta y constante esta distribución de sectas en los poetas españoles que puede ella sola servir de esqueleto a todo el cuerpo de su historia?». Corifeos y sectarios — continúa- constituyen un número reducido al lado de la multitud de nuestros poetas: «Convengamos pues en que el artículo de los poetas sueltos, que se añade después de enumeradas las escuelas, será más crecido que todas ellas juntas: será en una palabra la Historia de los poetas de España».

La segunda impugnación va contra la clasificación de las escuelas. En primer lugar por su número, que él reduce: «Para mí, de las siete escuelas que se señalan, sólo están averiguadas cuatro, a saber, la primera y la segunda italianas, la buena española y la española corrompida; esto es, la de Garcilaso, la de Herrera, la de Lope y la de Góngora». No son escuelas ni la de fray Luis de León, ni la de Villegas, ni tampoco la de los Argensolas, "si ya no quieren agregarse a León y formar con él una escuela latina, en la que ninguno imitó a otro, sino todos a Horacio» (matización esta última de sumo interés sobre la que volveremos).

Más allá va todavía Reinoso cuando ataca la clasificación de Arjona por su raíz y criterio: «Advierto que estas escuelas, cualesquiera que sean, deberán clasificarse, no sólo por el lenguaje, como parece que tal sucede en el Plan, sino por el estilo, o sea, por la manera de adornar los objetos y de expresar los conceptos fundamentales con otros pensamientos secundarios, que los presentan de este o de otro aspecto distinto. Porque en el estilo, entendido así, influyen inmediatamente el ingenio y la fantasía». Esta distinción entre lo interno del estilo y lo externo de la dicción permite a Reinoso (que se muestra así à la page de las teorías románticas del estilo y el genio individual) hacer hábiles distinciones entre Lope y Balbuena, hermanados por Arjona, e importantes apreciaciones sobre la poesía del Bachiller de la Torre, bien distante del «candor ingenuo, de la nativa sencillez y tersura griega» y que «en la frase y ornamento de la dicción se acerca mucho a nuestro Herrera».

Por último Reinoso, sin dejar de señalar que el cómico y el épico, unidos por Arjona en la escuela española, son «géneros distintísimos», pasa a la última objeción: las «mezclas» propuestas en el Plan. Ahora Reinoso - al que toda la razón asiste- es cuando se manifiesta con más dureza: «estas mezclas forman un caos oscurísimo, capaz de cegar al más despierto principiante» y «capaz de embrollar la cabeza al que quiera proponerse tres o cuatro modelos que copiar

11 Historia de las ideas estéticas, ob. cit., III, p. 263. 
a un tiempo». Por el contrario, Reinoso (haciéndose eco ahora de la más secular, pero no menos abstracta, teoría de la mímesis) propone que «la naturaleza es la que debe imitarse, la que debe estudiarse en sí misma». Finalmente concluye sus Reflexiones con una declaración de buenos propósitos — cortesía obliga- sobre el futuro desarrollo del Plan de Arjona.

Este desarrollo por extenso nunca se hizo. El Plan para una historia filosófica de la poesía española de Arjona no fue sino un proyecto primerizo, un discurso para la Academia de Letras Humanas que aglutinaba entusiasmos e ideas de estos jóvenes literatos. Reinoso, que compartió los mismos afanes de académico e incluso tuvo un papel relevante en la institución como secretario, además de ser en algún modo guía del grupo y encargado de defender sus propuestas estéticas llegado el caso ${ }^{12}$, escribe sus Reflexiones unos años después. El Plan de Arjona debe situarse, pues, en el tiempo de funcionamiento de la Academia, con 1800 como término ad quem. Escrito en los años finales del XVIII («tampoco incluiré en mi plan - dice- los poetas que han florecido, o que solamente han vivido desde mediados de este siglo), es probable que lo fuera después de $1797^{13}$, fecha en que aparece el volumen Poesías inéditas de Francisco de Rioja y otros poetas andaluces con un prólogo de Quintana que presumiblemente Arjona conocía, como luego veremos.

Reinoso, preocupado por estas cuestiones de historia literaria (según atestiguaría luego su magisterio como profesor y su futura Cátedra de Humanidades en la Sociedad Económica de Sevilla, para cuyo desempeñó ordenó un Curso filosófico de literatura), vuelve años más tarde, tal vez en el mismo de 1806, sobre el proyecto de Arjona, y da a conocer sus Reflexiones precedidas del Plan en el Correo Literario y Económico de Sevilla de 1806. El tono es distinto: el opúsculo de Arjona es una pieza oratoria que esboza con rapidez un proyecto; el de Reinoso es un tejido de juicios razonados, en el que, además, ha desaparecido la finalidad pragmática de adoctrinamiento a los jóvenes poetas, para centrarse en la reflexión teórica. Pero, en todo caso, ambos están hermanados por un propósito común: el de buscar por primera vez una sistemática en el estudio de la poesía española. Un punto más que une a estos dos hombres, de vocación y formación parejas, que primero compartieron experiencias juveniles en la constitución de una pretendida moderna escuela sevillana, y luego — también en paralelo- el destino histórico, con la invasión napoleónica, los enredó en complicados azares y los hizo víctimas de no pocos recelos por su connivencia con la causa afrancesada $^{14}$.

12 Véase nota 8.

13 Tras el regreso, por tanto, del viaje que en 1797 hace Arjona a Roma acompañando al cardenal Despuig y Dameto (Para las biografías de Arjona y Reinoso véase la bibliografía citada en notas 3, 4, 6 y 10; y para Reinoso en particular la realizada por Antonio Martín Villa y publicada al frente de las Obras de Reinoso, Sevilla, Soc. de Bibliófilos Andaluces, Imp. de Rafael Tarasco, 1872), y ahora el estudio de R. Ríos Santos, Félix José Reinoso (1772-1841), Vida y obra, Tesis Doctoral actualmente en prensa en el Servicio de Publicaciones de la Diputación Provincial de Sevilla).

14 Reinoso llegó a significarse más en este sentido como autor de un Examen de los delitos de infidelidad a la patria, imputados a los españoles bajo la dominación francesa (1. ed. francesa de 1816), polémico escrito según da fe el testimonio posterior de Bartolomé José Gallardo. Éste, al iniciar la copia de unos fragmentos del Elogio al Licenciado Pacheco de Porras de la Cámara, se refiere, 
Pasando ya al análisis crítico de esta primera tentativa organizadora del legado poético español llevada a cabo por Arjona y Reinoso, hemos de fijarnos en primer lugar en los patrones y valores estéticos de estos hombres de finales del siglo XVIII y principios del XIX, base para su modus operandi en la práctica historiografía. Como buenos herederos del espíritu ilustrado, Arjona y Reinoso comulgan de pleno con los valores clasicistas, con ese aire de clasicismo afectado o neo que dio el siglo XVIII (y más sus epígonos sevillanos del XIX) en su empeño de ruptura con los últimos coletazos barrocos y en su afán por repristinar la poesía española a lo Garcilaso y fray Luis, de quienes, en el fondo, estaban tan lejos. Con todo, estos poetas sevillanos decantan más su gusto hacia la alta entonación herreriana que hacia el puro clasicismo garcilasiano, aspecto que comparten Arjona y Reinoso, si bien a su vez entre ellos hay diferencias de matiz significativas. A Arjona le parece que Garcilaso «aunque generalmente no sea muy correcto, ni del gusto más delicado, su nativa belleza y dulzura merecieron la aprobación y aun admiración de todas las personas sensatas, y tuvo bastantes imitadores». Pero en Herrera (a pesar de ser el fundador de la escuela sevillana «ya enteramente perfecta en su género») también encuentra un defecto: «él es como un grandioso salón, en el que el pavimento, el techo, las paredes, las estatuas, todo es de oro; pero en el mismo hecho de ser todo de oro le falta aquella amena variedad que recrea la vista, y que es más agradable que la riqueza más magnífica». Para Reinoso, que nada dice de Garcilaso, salvo el ser introductor con Boscán y Hurtado de Mendoza de un nuevo estilo, desaparece cualquier sombra de duda hacia el lenguaje herreriano, pronunciándose de manera que se hará tópica en toda la historiografía del siglo XIX: «Fernando de Herrera mejoró después el nuevo estilo, lo enriqueció con galas más exquisitas, lo varió con la imitación de los latinos y griegos, lo sublimó con la grandeza y rapidez de una imaginación pindárica, y creó un nuevo género, que fue seguido después por muchos poetas de su patria». Diferencia de matiz hay también en la apreciación de ambos sobre fray Luis. Si a Arjona le parece «incomparable», Reinoso piensa que los Argensola modificaron aquel estilo [latino y horaciano] «con una imaginación más severa y menos sensible que la de León y un ingenio más profundo que el suyo». La desigual apreciación entre Arjona y Reinoso denota diferencias de grado en su concepción del lenguaje poético y se refleja, en última instancia, en su propia labor creativa: mientras que Arjona pasa por ser el poeta más espontáneo de la moderna escuela sevillana, Reinoso es el más trabajado y artificioso. Mucha razón tenía L. A. de Cueto al afirmar que el primero era poco proclive a imitar la entonación solemne de Herrera y más a seguir las huellas de fray Luis de León y Francisco de Rioja ${ }^{15}$ (afirmación esta que apunta además, y sin querer, a otra

como marco ambiental, a la poesía sevillana del Siglo de Oro, y aprovecha para decir entre paréntesis: «Hablo de la verdadera Escuela Sevillana, que fundaron en el último tercio del siglo XVI los Pachecos, los Malaras, Girones, Tamarizes, Quiroses, Medinas, etc., y que tanto honraron últimamente los Herreras, Arguijos y Riojas; no de esa mentida, que desvanecidamente quieren ahora llamar Escuela Sevillana los Reinosos y los Listas: los cuales, si han formado escuela, no ha sido de poesía, sino del molinismo político que se enseña en el Examen de los delitos de infidelidad contra la Patria» (El Criticón, papel volante de Literatura y Bellas Artes, Madrid, Imp. de Sancha, 1835, p. 18).

15 «Bosquejo histórico-crítico...», ob. cit., p. CXCI. 
verdad de fondo sobre la que luego volveremos: la falsedad de un concepto unitario de escuela poética sevillana en el Siglo de Oro bajo el magisterio de Herrera, noción errónea en la que no cayeron los autores del Plan y las Reflexiones).

Pero esas diferencias de grado en la apreciación y en la práctica poética no separan a Arjona y Reinoso en su convicción estética clasicista de fondo. Por eso ambos son unánimes - Arjona explícitamente, Reinoso al aceptar la existencia de una escuela española corrompida - en condenar al artifex maximus del gusto barroco más reprobable, es decir, Góngora, no sin dejar de distinguir entre el Góngora de las «buenas poesías» del otro.

Vemos, por unas y otras cosas, que las premisas y los planteamientos serán prácticamente los mismos que se dejen oír a lo largo de todo el siglo XIX. Tras la lima de Reinoso, queda trazado en sus líneas más generales el mapa de la historia de la poesía áurea que se hará prototípico: para el siglo XVI, la escuela de Garcilaso, de imitación italiana fundamentalmente ${ }^{16}$, y la de Herrera (del que se exaltará sobre todo la faceta pindárica de sus canciones y la inspiración bíblica) o sevillana, que eleva e intensifica la anterior; para el siglo XVII, los logros más genuinos se reservan a la denominada escuela española, que con el tiempo se irá consolidando en su asociación fundamental a la dramática en los dos principales ciclos, el lopesco y el calderoniano, sin dejar de incluir en la misma escuela a la épica de corte histórico-nacional; por otra parte, y en cuanto a la lírica, el siglo XVII será — desde esta historiografía decimonónica- escenario de un proceso de degradación, que se entenderá como vicio de forma, culteranismo, o de contenido, conceptismo, distinciones que, sin embargo, no aparecen en las páginas del Plan ni de las Reflexiones, donde ni siquiera, y curiosamente, se cita el nombre de Quevedo poeta, aunque sí el aludido tópico de los dos Góngoras.

En este esquema básico del mapa de las escuelas poéticas prefigurado por Arjona y Reinoso faltaba, sin embargo, el apunte de una de las más significadas del XVI: la escuela salmantina, que junto con la sevillana completaba el panorama de la poesía renacentista en una bifurcación que se interpretaba casi antagónica a partir del legado de la primera mitad del XVI. Es verdad que Arjona se refirió a una escuela de fray Luis, que él denominó hispano-latina, pero señalando que «esta senda se ha quedado en vano abierta, y aun casi ya no se conoce, pues desde fray Luis de León nadie la ha pisado». Parece claro que Arjona perdía de vista una noción de conjunto más amplia, que Reinoso apuntó de manera inteligente: tampoco los Argensola habían formado escuela, «si ya no quieren agregarse a León y formar con él una escuela latina, en la que ninguno imitó a otro, sino todos a Horacio». Interesante afirmación que de haberse seguido en la posteridad hubiera evitado un excesivo fraccionamiento en compartimentos estancos que gravitó particulamente en nociones regionales, pues la escuela salmantina se

16 Conviene recordar de nuevo la atinada afirmación de Menéndez Pelayo (véase nota 11) a propósito del error de Arjona de «considerar meramente como italo-hispana a la poesía de Garcilaso, que debe su mayor belleza a elementos clásicos puros virgilianos y horacianos». Tal impugnación podría hacerse en alguna medida todavía hoy, un siglo después, pues, en efecto, siempre se ha primado en exceso en los estudios garcilasianos la orientación italianista o petrarquista en detrimento de la clásica. 
hizo casi única y exclusiva acreedora de la línea horaciana ${ }^{17}$, cuando también lo eran, además de los aragoneses Argensola, los sevillanos de principios del XVII como Fernández de Andrada, Rioja y por supuesto Medrano, cuyo manifiesto horacianismo ha sido precisamente motivo para aislarlo del grupo sevillano e incluirlo en el salmantino. Con razón había matizado Arjona que «no todos los poetas sevillanos son de esta escuela sevillana», advertencia que fue desoída en lo sucesivo.

Esta cuestión merece ser atendida con más detenimiento, pues el proyecto de Arjona y Reinoso supone la primera conceptualización de una escuela sevillana del Siglo de Oro ${ }^{18}$. No olvidemos que estos poetas de fines del XVIII-principios del XIX son los primeros interesados en la configuración de una escuela de la que ellos serían directos imitadores, a más de garantes de tan gloriosa tradición poética por estar radicados en el mismo medio. Arjona y Reinoso aíslan a la escuela sevillana, le ponen nombre y le tributan los mayores elogios de entre el resto de las peninsulares. Pero - y es lo más importante- la noción de escuela sevillana es además la que les sirve de patrón metodológico para establecer el mapa de las restantes. Si en el Plan de Arjona la idea permanece implícita, Reinoso la descubre: «Fernando de Herrera [...] fue seguido después por muchos poetas de su patria. Ahora bien: ¿por qué no podrán clasificarse a esta manera los demás poetas españoles, y hallado que sea el inventor de un nuevo estilo, separarle con sus imitadores en clase diversa de los restantes? Tal es el fundamento y aun el mismo Plan por mayor». La cuestión es harto interesante: la escuela poética sevillana es la primera que aparece configurada desde la moderna historiografía. Ahora bien, ¿eran Arjona y Reinoso responsables de tal conceptualización o acogían en ello ideas previas?

Si buscamos una perspectiva crítica en el estudio de la poesía española, hemos de esperar a las Poesías selectas castellanas de Quintana publicadas en $1808^{19}$. En ellas el importante caudal poético recogido se analiza de manera orgánica en el prólogo, con lo que esta antología de Quintana deja muy atras a las dos colecciones poéticas, voluminosas e importantes ambas, que le habían precedido: el Parnaso español de López de Sedano ${ }^{20}$ y la Colección de poetas españoles por D. Ramón Fernández (pseudónimo de Pedro Estala) ${ }^{21}$. Pero ya esta última ofrece datos de interés para lo que ahora nos importa en dos de sus prólo-

17 Idea que se iba fraguando a lo largo del siglo XIX y tomó decididamente cuerpo en la obra de Menéndez Pelayo, Horacio en España, Madrid, Imp. de A. Pérez Dubrull, 1885, 2 vols.

18 La noción de escuela poética sevillana es, en efecto, una noción moderna. Cfr. al respecto el importante trabajo de Henry Bonneville, "Sobre la poesía de Sevilla en el Siglo de Oro», Archivo Hispalense, LV, 1972, pp. 79-112. Bonneville, que hace un inteligente repaso de la bibliografía del XIX responsable del concepto de escuela sevillana, sin embargo sólo cita de pasada el Plan de Arjona y las Reflexiones de Reinoso.

19 Poesías selectas castellanas desde el tiempo de Juan de Mena hasta nuestros días, recogidas y ordenadas por Manuel Josef Quintana, Madrid, Gómez Fuentenebro y Cía, 1808, 3 vols. Nueva ed. aum. y corr., Madrid, Imp. de D. M. de Burgos, 1830, 4 vols.

20 Parnaso español. Colección de poesías escogidas de los más célebres poetas castellanos [Tomos VI-IX por Juan Joseph López de Sedano], Madrid, Ibarra, 1768-1779, 9 vols.

21 Madrid, Imprenta Real, 1786-1804, 20 vols. 
gos: el de Estala a las Rimas de Fernando de Herrera (1786, vols. IV y V de la Colección) y el de Quintana a las Poesías inéditas de Francisco de Rioja y otros poetas andaluces (1797, vol. XVIII).

Estala había destacado el esfuerzo de Herrera «en enriquecer nuestra lengua de infinitos modos de decir poéticos de que antes carecía» y ponderado dos aspectos principales: su fantasía ardiente y viva, y la sublimidad de su lenguaje poético, manifiesta sobre todo en la imitación de la poesía hebraica. Por los mismos senderos del elogio herreriano sigue Quintana, pero introduce además otro elemento: el magisterio de Herrera entre sus paisanos como fundamento de una escuela poética. Ya la publicación de un volumen como las Poesías inéditas de Francisco de Rioja y otros poetas andaluces, en el que sólo Céspedes, entre los autores recogidos, no era sevillano, no es tal vez extraña - como apuntó certeramente Bonneville 22 - al nacimiento de la idea de escuela. En todo caso, Quintana la hace explícita al afirmar que Herrera fue «anterior a Rioja, y tal vez su maestro», y al caracterizar el lenguaje poético andaluz como «más ardiente y vigoroso que el de los castellanos y aragoneses».

Es casi seguro que las opiniones de Estala y Quintana fueron conocidas y aprovechadas por Arjona y Reinoso. Pero ni uno ni otro avanzaron en la peligrosa dirección de suponer únicamente el magisterio herreriano como fundamento de la escuela. Ya vimos la matización de Arjona de que no todos los sevillanos serían de esa escuela... Y, por cierto, no deja de ser curioso que ni él ni Reinoso nombren a solo uno de los poetas sevillanos del XVII, ni siquiera a Rioja, el poeta filósofo que debía hacer las delicias de estos hombres de gustos clasicistas. Tal vez la cita de estos poetas les hubiera obligado a hacer unos distingos poco prácticos en un proyecto tan general, y sobre todo hubiera roto la pretendida uniformidad de la escuela sevillana.

Tras Arjona y Reinoso la noción de escuela sevillana fue tomando cada vez más cuerpo. El propio Quintana vuelve sobre ella en 1808 en sus Poesías selectas castellanas. En el prólogo reitera las características del lenguaje poético andaluz frente al castellano: tono más elevado y vehemente, enriquecimiento y engalanamiento de la dicción, intención de sorprender y arrebatar. Y por fin establece el magisterio de Herrera: le imitó Arguijo..., pero fue Rioja quien «lo mejoró infinitamente más». He ahí ya los dos tópicos de que se nutrirá el concepto de escuela poética sevillana en lo sucesivo: la verbosidad y riqueza de la dicción, por una parte, y el eje Herrera maestro-Rioja mejor discípulo, por otra. En este último sentido Quintana fijó también otro hito: al ordenar las poesías de Rioja en la colección se encuentra con el problema de su cronología tardía respecto a Herrera. Entonces una peculiar habilidad le permitió enhebrar una línea histórica discutible, pero que iba a sentar un importante precedente para la posteridad: «Aunque bastante posterior a Herrera, se colocan aquí sus poesías en este lugar [es decir, tras Herrera] por ser de la misma escuela y más análogas en gusto y carácter a las de este autor que a las de sus contemporáneos» ${ }^{23}$.

22 «Sobre la poesía de Sevilla en el Siglo de Oro», art. cit., p. 82.

23 Poesías selectas castellanas, ob. cit., I, p. 163 (cito por la ed. de 1830). 
En otros lugares ${ }^{24}$ he discutido el concepto de escuela poética sevillana desde la pretendida unidad que le presta el magisterio herreriano, pues los poetas sevillanos del XVII, y por tanto Rioja, aunque arrancan del modelo poético de Herrera, y a veces sus calcos léxicos y estilísticos son palpables, tienen su centro de interés en otra esfera de la génesis poética; en ellos el fondo ético se va perfilando como generador fundamental, y a través de la imitación horaciana y del pensamiento neoestoico, adoptan un discurso poético suasorio lejano a la solemnidad y verbalismo herrerianos. Pero el concepto metodológico de escuela, tan caro a la historiografía del siglo XIX, tenía precisamente su basamento en la noción de magisterio que se acepta y asume por discípulos. Incuestionable pues el principio de liderazgo, éste se asignó a Herrera y Rioja asumió el del «mejor discípulo». Pero la dualidad de lenguajes poéticos no pasó desapercibida ni a estudiosos como Quintana, ni a panegiristas como Angel Lasso de la Vega ${ }^{25}$, que no sólo dejaron traslucir en sus obras un doble liderazgo (Herrera-Rioja), sino que además mostraron, dados sus presupuestos estéticos, una adhesión más incondicional hacia el «melancólico cantor de las flores» que hacia el mismo Herrera, del que, en todo caso, exaltaron la faceta pindárica por encima de la petrarquista.

Pero estas son cuestiones de más amplia envergadura, de las que me ocupo aparte. Valga aquí decir que el concepto de escuela poética sevillana que se va consolidando a lo largo del XIX (y que en su tercio final tiene una aportación de relieve con Menéndez Pelayo ${ }^{26}$ ) surge de la interacción de tres principios fundamentales: de los criterios clasicistas (que hubieron de defender a Herrera de toda contaminación con fenómenos poéticos barrocos), de las teorías deterministas, tan de moda en el XIX, y especialmente del factor medio, y -en relación con el anterior- de un manifiesto chauvinismo, puesto de manifiesto en las voces y publicaciones locales, de considerar a la escuela sevillana como la acreedora de las mayores glorias poéticas ${ }^{27}$. Pero — como decía- ese es tema que cae fue-

24 La poetica cultista de Herrera a Góngora, Sevilla, Alfar, 1987, pp. 75-139; Introducción a la ed. Francisco de Rioja. Poesía, Madrid, Cátedra, 1984, pp. 41-48 y 85-88; «El Cancionero de Fonseca y el Ms. 3888 de la Biblioteca Nacional de Madrid», Homenaje a Antonio Gallego Morell, Universidad de Granada (en prensa).

25 Historia y juicio crítico de la escuela poética sevillana de los siglos XVI y XVII, Madrid, Imp. de la Viuda e Hijos de Galiano, 1871.

26 En varias de sus obras: en los tomos II (1884) y III (1886) de su Historia de las ideas estéticas, ob. cit. (en el II al hablar de las escuelas poéticas en el Siglo de Oro; en el III, antes citado, al hablar de la moderna sevillana) y en el prólogo a las Poesías divinas y humanas del P. Pedro de Quirós, Sevilla, Soc. del Archivo Hispalense, 1887.

27 Valga como ejemplo la caracterización que de la misma hace el propio Félix José Reinoso en su colaboración para el Diccionario geográfico de España y Portugal (1826-1829) de Sebastián Miñano: «En Herrera, y con más economía en los nombrados primeramente, que forman la escuela clásica sevillana, se muestran, ora la fuerza, ora la belleza de los pensamientos e imágenes, no mezcladas por lo común con el desaliño que a veces se encuentra en Garcilaso, ni con el desmayo y falta de sonoridad no infrecuentes en León, ni expresadas con la sequedad de los Argensolas, ni manchada con los extravíos de Góngora y Villegas, ni desagradadas por el prosaismo general de todos; sino enriquecidas con un estilo más fecundo y correcto, y una dicción más escogida y adornada, suelta y voluble a veces tanto como la de Lope, pero siempre más llena y rica, pero nunca o rara vez debilitada por su incuria y vulgaridad, ni deslucida con la multitud de lunares que hacen insufrible la lectura de las más graves composiciones de aquel genio feraz, corrompido y abandonado» (Tomo VIII, p. 256). 
ra de estas páginas. El objetivo de las mismas ha sido el estudio de un proyecto juvenil de Arjona y Reinoso cuyo máximo alcance está en el valor relativo de haber dado los primeros pasos en la fijación del concepto de escuela poética sevillana ${ }^{28}$ y en el más amplio de su primacía en prefigurar el mapa de la historiografía poética española *

28 El Plan de Arjona tuvo, por lo demás, importante repercusión local si tenemos en cuenta que la Academia Sevillana de Buenas Letras abre concurso en 1839 sobre idéntico tema: «si podrían clasificarse en escuelas los poetas españoles como los pintores se clasificaban». El certamen quedó desierto, pero la Academia siguió en su empeño, convocando nuevo concurso en 1867, ahora ya sobre la escuela sevillana en particular, concurso que ganó Lasso de la Vega con la monografía citada, nota 25 (Cfr. Bonneville, «Sobre la poesía de Sevilla en el Siglo de Oro», art. cit., pp 84 y 86).

* Después de entregado este trabajo, otros avatares investigadores me llevaron a consultar las Actas de la Academia de Letras Humanas que se conservan en el Archivo Universitario de Sevilla (333/209). Comienzan éstas el 10 de mayo de 1793 y terminan el 8 de enero de 1797, no constando en ellas que se hubiera leído el Plan de Arjona en ninguna de las sesiones celebradas en ese tiempo. Más fortuna tuve al revisar la «Historia de la Academia de Letras Humanas de Sevilla, desde su establecimiento hasta el 10 de mayo de 1799, por D. Félix José Reinoso, académico y secretario de la misma», Archivo Hispalense, 1. época, II (1886), pp. 25-40, 49-64, 129-144 y 152-175. En un «Catálogo de los trabajos leídos por sus autores en la Academia...» allí contenido (pp. 162-173) se registra que Manuel María de Arjona leyó su Plan para una Historia filosófica de la poesía española el 19 de diciembre de 1798. No consta, sin embargo, que Reinoso leyera en la Academia sus Reflexiones... Todo ello no viene, pues, sino a confirmar mis hipótesis antes expuestas sobre la diferente finalidad de ambos opúsculos y sus distintas fechas de realización.

Por otra parte, ya en prensa este artículo, llegó a mis manos el de Ramón Morillo-Velarde, «El 'Plan para una historia filosófica de la poesía española' de Manuel Ma de Arjona», Alfinge, 2 (1984), pp. 155-161, en el que se recoge que el Plan también fue leído por su autor en una de las primeras sesiones de la Academia de Ciencias, Bellas Letras y Nobles Artes de Córdoba, de la que Arjona fue miembro fundador en 1810 . 
